\title{
Progression of disease in ocular cicatricial pemphigoid
}

\author{
Mark J Elder, Wolfgang Bernauer, Jonathan Leonard, John K G Dart
}

\begin{abstract}
Background-Ocular cicatricial pemphigoid (OCP) is a sight threatening autoimmune disease that can lead to severe conjunctival cicatrisation and keratopathy. It has a variable course and little is known about the factors that determine disease progression. This study analysed the factors that have prognostic significance regarding disease outcome,
\end{abstract} progression, and keratopathy.

Methods-Sixty six patients with OCP were monitored prospectively at Moorfields Eye Hospital. The influence of ocular features, the systemic disease, and the management were analysed to identify factors that influence the outcomes and disease progression.

Results-The mean age at presentation was 67 years; $56 \%$ were men. The binocular visual acuities were $6 / 24$ or worse in $25 \%$. Extensive cicatrisation at presentation was common but correlated only weakly with the visual prognosis. Systemic manifestations included lesions of the mouth in $44 \%$, pharynx in $30 \%$, oesophagus in $27 \%$, nose/sinus in $18 \%$, and skin in $17 \%$. There was no association between the ocular and systemic manifestations. Persistent corneal epithelial defects and limbitis occurred in $18 \%$ and $32 \%$, respectively, and both were associated with a worse visual prognosis. Systemic immunosuppression was ultimately prescribed in $74 \%$, mainly in patients with advanced stages of conjunctival cicatrisation. Of patients with more than 24 months follow up, progression of cicatrisation occurred in $35 \%$ of eyes (16/46) all but one of which were associated with episodes of conjunctival inflammation.

Conclusions-Persistent epithelial defects, limbal inflammation, and ongoing conjunctival inflammation are important factors that lead to keratopathy and visual handicap. These require aggressive management, often with systemic immunosuppressive treatment. Close follow up is required in cases with extensive cicatrisation.

(Brf Ophthalmol 1996; 80: 292-296) Praed Street, London W

$\mathrm{J}$ Leonard

Correspondence to: Mark J Elder, Department of Ophthalmology, Christchurch Hospital, PO Box 4710, Christchurch, New Zealand.

Accepted for publication 21 December 1995
Ocular cicatricial pemphigoid (OCP) is an inflammatory and cicatrising disease of the conjunctiva and mucous membranes that causes severe visual handicap in up to one third of patients. ${ }^{1}$ The disease is characterised by the abnormal binding of immunoglobulins to the basement membranes of the skin and mucous membranes. ${ }^{2-4}$ Acutely, this causes complement activation and infiltration of the conjunctiva by neutrophils, macrophages, and activated $T$ cells. ${ }^{5-7}$ The scarring is a consequence of this. The key ocular features are the conjunctival fibrosis and the keratopathy. Once these have occurred, the prognosis for visual of rehabilitation is poor and, therefore, the prevention of disease progression is important. ${ }^{8}$ This study presents data from a prospective study of a large cohort of patients and analyses the factors that have prognostic significance regarding disease progression and the keratopathy. These data may improve management and allow more appropriate follow up.

\section{Materials and methods}

Patients attending the corneal and external disease clinics of Moorfields Eye Hospital were assessed prospectively and the data recorded. OCP was diagnosed on the characteristic clinical and laboratory features. Other causes of cicatrisation, such as previous infection or drug associated cicatrisation, were excluded. Conjunctival biopsy was performed on all but nine patients and was defined as positive if there was immunostaining showing linear basement membrane deposition of IgG, IgA, or complement as demonstrated by immunofluorescence on frozen sections. ${ }^{34}$ This technique reveals no staining of the basement membrane of conjunctiva and skin from patients without OCP. ${ }^{34}$

Each eye was staged using both Mondino's ${ }^{3} 10$ and Foster's ${ }^{11}$ classification systems. Mondino's classification quantifies inferior fornix depth loss; stage II is a reduction of $25-50 \%$, stage III, $50-75 \%$. Normal depth is approximately $11 \mathrm{~mm} .{ }^{12}$ Foster's staging uses specific clinical signs; stage II any fornix shortening, stage III - symblepharon, stage IV - ankyloblepharon. Data in this study extend from October 1991 to October 1994 and include patient characteristics, visual acuities, specific ocular findings, systemic features, and patient management.

Progression of disease was defined as a shift from one stage to another and was assessed in a cohort of patients with 24 months or more of follow up. For all patients, the ocular and systemic features were correlated with the final outcomes of visual acuity and the amount of cicatrisation. The visual acuity data were from the last clinic assessment in order to exclude the effects of acute disease. If there was an acute or subacute cause for reduced visual acuity, then the acuity was recorded from the 


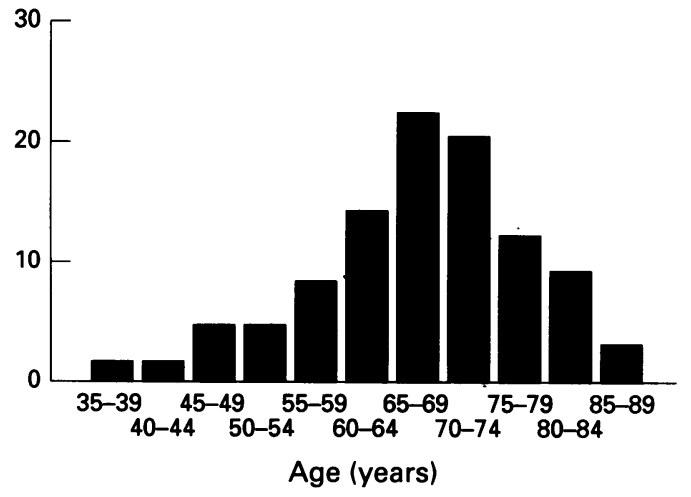

Figure 1 Age at initial presentation.

contiguous, preceding visit when the problem was not present. Visual acuity was classified into the WHO definitions of 'visual impairment' $(>6 / 18-6 / 60)$, 'severe visual impairment' $(>6 / 60)$, and 'blind' $(>3 / 60)$. All $\chi^{2}$ tests used Yates's correction.

Particular regard was given to any associations with corneal disease. A quantitative assessment of the degree of chronic corneal involvement was made from the visual acuity after all cases with non-corneal causes of reduced visual acuity were excluded. Specific acute or subacute corneal problems were persistent epithelial defects (PED), limbitis, and acute microbial keratitis. PED was defined as an area of cornea that was not covered by epithelium for 1 month or more, despite treatment. This did not include punctate epithelial keratopathy. Limbitis was defined as a raised, inflamed region involving the limbal tissues extending for one quadrant or more. To assess whether limbitis was associated with any of the specific systemic manifestations of ocular cicatricial pemphigoid, the patients were divided into those that had bilateral limbitis and those that had never had limbitis in either eye.

\section{Results}

This study reports data from 132 eyes of 66 patients of whom the mean age (SD) was $67 \cdot 1$ $(10.9)$ years and ranged from $37-88$ years. The male:female ratio was $37: 29(1 \cdot 3: 1)$. The age at presentation, visual acuities, and stages of disease are detailed in Figures 1 and 2 and Table 1. Conjunctival biopsies were obtained from 57/66 patient and were positive in $54 \%$ (31/57). The bound products were IgA $74 \%$ (33/31), IgG 42\% (13/31), complement C3 $52 \%(16 / 31)$, fibrinogen $42 \%(13 / 31)$, and

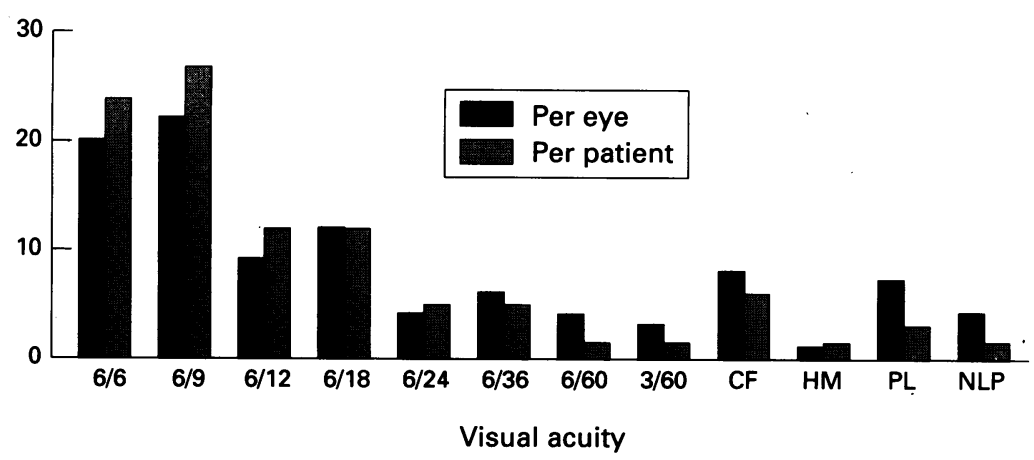

Figure 2 Visual acuity per eye and per patient at initial presentation.
IgM 13\% (4/31). This compares with biopsies of non-lesional skin of $50 \%, 33 \%, 17 \%, 0 \%$, $17 \%$ respectively from 12 of these patients. Thirteen patients had reduced visual acuity caused by pathology other than corneal disease; cataract $(n=6)$, macular degeneration $(n=4)$, glaucoma $(n=2)$, and amblyopia $(n=1)$. These patients were excluded in the assessment of associations with corneal disease.

For Foster's staging system, the proportion of eyes classified as stages I-IV were $2 \%, 33 \%$, $61 \%$, and $14 \%$ respectively (Table 1 ). Those eyes that were stage IV had a worse visual acuity than stage III for visual impairment and severe visual impairment $\left(\chi^{2}, p=0.003\right.$ and $\mathrm{p}=0.0001,95 \%$ confidence intervals $(\mathrm{CI})$, $1 \cdot 1-1 \cdot 8$ and $1 \cdot 3-2 \cdot 7)$. For Mondino's staging system, the proportion of eyes classified as stages I-IV were $4 \%, 20 \%, 34 \%$, and $42 \%$ respectively (Table 1 ). There was no statistical association between any stage and the visual acuity. However, there was a trend between stage IV and blindness $\left(\chi^{2}, p=0.06,95 \%\right.$ $\mathrm{CI}=0 \cdot 96-3 \cdot 7)$. For corneal disease solely, there were statistically significant differences between Foster's stage III and IV at both the level of visual impairment and severe visual impairment $\left(\chi^{2}, \mathrm{p}=0.001, \mathrm{p}=0.0001,95 \%\right.$

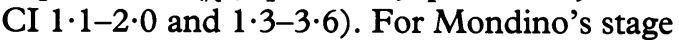
III and IV, there was a trend at the level of severe visual impairment $\left(\chi^{2}, p=0.052,95 \%\right.$ CI 0.97-4.9).

The ocular manifestations occurred in 100\% of patients and systemic manifestations occurred in $50 \%$. These included lesions of the mouth $44 \%$, pharynx $30 \%$, nose/sinus $18 \%$, oesophagus $27 \%$, anus $5 \%$, vagina $5 \%$, and skin $17 \%$. There was no statistically significant association between the prevalence of systemic manifestations of OCP and the visual acuity of each patient $\left(\chi^{2}, p>0.05\right)$, nor was there an association between the systemic manifestations and visual acuity reduced solely because of corneal disease $(n=53, p>0.05)$.

Systemic immunosuppressive drugs were required in $74 \%$ of patients $(49 / 66)$ at some stage of the disease. This was because of an inadequate response to topical immunosuppression and management of the ocular surface disease or because of moderate or severe inflammation. ${ }^{13} 14$ Agents used included prednisolone (30\%, 20/66), cyclophosphamide $(17 \%, 11 / 66)$, azathioprine $(5 \%, 3 / 66)$, dapsone $(15 \%, 19 / 66)$, sulphapyridine $(33 \%$, $22 / 66)$, and sulphamethoxypyridazine (12\%, $8 / 66)$. Two additional patients were on steroids other than for OCP (Crohn's disease (one) and rheumatoid arthritis (one)). The group of patients who did not require systemic immunosuppression $(26 \%, 17 / 66)$ had a mean age (SD) of $67 \cdot 1(13 \cdot 6)$ years with a range 42-88 years. The comparison of the patients that did and those that did not require systemic immunosuppression is given in Tables 2 and 3. There was no statistically significant difference between the two groups regarding their ultimate visual acuity or the prevalence of the systemic manifestations of OCP. However, $62 \%$ of those who did not require systemic 
Table 1 Ultimate visual acuity and the ocular staging (per eye)

\begin{tabular}{|c|c|c|c|c|c|}
\hline \multirow[b]{2}{*}{ Staging } & \multicolumn{5}{|c|}{ Visual acuity } \\
\hline & $6 / 6^{*}-6 / 18$ & $6 / 24-6 / 60$ & $>6 / 60-3 / 60$ & $>3 / 60$ & Total \\
\hline $\begin{array}{l}\text { Foster's } \\
\text { I } \\
\text { II } \\
\text { III } \\
\text { IV }\end{array}$ & $\begin{array}{r}2(67 \%) \\
23(77 \%) \\
53(66 \%) \\
5(26 \%)\end{array}$ & $\begin{array}{l}- \\
5(17 \%) \\
13(16 \%) \\
-\end{array}$ & $\begin{array}{l}- \\
1(3 \%) \\
3(4 \%) \\
-\end{array}$ & $\begin{array}{c}1(33 \%) \\
1(3 \%) \\
11(14 \%) \\
14(74 \%)\end{array}$ & $\begin{array}{r}3 \\
30 \\
80 \\
19\end{array}$ \\
\hline $\begin{array}{c}\text { Mondin } \\
\text { I } \\
\text { II } \\
\text { III } \\
\text { IV } \\
\text { Total }\end{array}$ & $\begin{array}{c}5(100 \%) \\
20(77 \%) \\
27(60 \%) \\
31(55 \%) \\
83(63 \%)\end{array}$ & $\begin{array}{c}- \\
4(15 \%) \\
9(20 \%) \\
5(9 \%) \\
18(14 \%)\end{array}$ & $\begin{array}{l}\overline{1}(4 \%) \\
2(4 \%) \\
1(2 \%) \\
4(3 \%)\end{array}$ & $\begin{array}{c}- \\
1(4 \%) \\
7(16 \%) \\
19(34 \%) \\
27(20 \%)\end{array}$ & $\begin{array}{r}5 \\
26 \\
45 \\
56 \\
132\end{array}$ \\
\hline
\end{tabular}

${ }^{\star}$ Best corrected visual acuity.
$(13 \%)$ at some stage during the disease. Using Mondino's staging, four eyes were stage II, three eyes were stage III, and 10 eyes were stage IV; hence $10 / 17$ eyes with PED had less than $3 \mathrm{~mm}$ of inferior fornix. The PED occurred in 8/12 patients and $11 / 17$ eyes while they were on systemic immunosuppression. This included regimens such as $5-30 \mathrm{mg}$ of prednisolone, dapsone, sulphapyridine, azathioprine, cyclophosphamide, and combinations of the above. One eye had a PED associated with rapidly recurrent trichiasis and $6 / 17$ eyes had a previous episode of limbitis. There were no other predisposing factors. Only 3/17 eyes were on topical steroids at the time. The final visual outcomes of these eyes were assessed 6 months after epithelial healing $(n=17)$. This time was sufficient to allow visual rehabilitation but insufficient to allow disease progression to further impair the visual acuity. Only $4 / 17$ eyes had an acuity of $6 / 60$ or better $(6 / 36,6 / 9,6 / 6,6 / 6)$. One patient, with long standing glaucomatous optic atrophy had no perception of light after acute penetrating keratoplasty. Bacterial keratitis occurred in three eyes of three patients, with one patient having another episode in the same eye 6 months later. One eye perforated and required acute keratoplasty while all the others responded to intensive topical antibiotics.

Bilateral limbitis occurred in 16/66 (24\%) patients and unilateral limbitis occurred in $5 / 66(8 \%)$. This represented $37 / 132(28 \%)$ of eyes. The results of the ultimate visual acuity and the occurrence of an episode of limbitis are detailed in Table 4. There is a statistically significant association between having an episode of limbitis and having a poorer final visual outcome in that eye $\left(\chi^{2}, p>0.001\right)$. There was no statistically significant difference between the prevalence of the systemic manifestations of OCP among those patients who developed bilateral limbitis and those who did not $\left(\chi^{2}, p=0.05\right)$. during episodes of conjunctival inflammation. This was related to corneal incision cataract surgery while not on systemic immunosuppression $(n=1)$, treatment with topical steroids alone $(n=1)$, recurrence after stopping dapsone $(n=1)$, still being treated with dapsone $(n=9)$, and still being treated with cyclophosphamide $(n=3)$. Therefore, $12 / 16$ eyes progressed while on oral immunosuppression.

\section{CORNEAL COMPLICATIONS OF OCP}

Persistent epithelial defects (PED) occurred in $12 / 66$ patients (18\%) and in $17 / 132$ eyes

\section{Discussion}

This study demonstrates the spectrum of disease in a population of patients with OCP and examines the natural history in a subgroup of patients with 2 or more years of follow up. The current staging systems correlate poorly with corneal disease that leads to visual loss. Table 1 shows that Mondino's system has a more uniform distribution of patients per stage. This would be expected as it is based on the inferior fornix depth which is a continuous variable whereas Foster's system is based on

Table 2 Ultimate visual acuity for those who did and did not receive systemic immunosuppression

\begin{tabular}{|c|c|c|c|c|c|c|}
\hline Visual acuity & $\begin{array}{l}\text { No systemic } \\
\text { treatment } \\
\text { (per eye) }\end{array}$ & $\begin{array}{l}\text { Systemic } \\
\text { treatment } \\
\text { (per eye) }\end{array}$ & Total & $\begin{array}{l}\text { No systemic } \\
\text { treatment } \\
\text { (per patient) }\end{array}$ & $\begin{array}{l}\text { Systemic } \\
\text { treatment } \\
\text { (per patient) }\end{array}$ & Total \\
\hline $\begin{array}{l}6 / 6^{\star}-6 / 18 \\
>6 / 18-6 / 60 \\
>6 / 60-3 / 60 \\
>3 / 60 \\
\text { Total }\end{array}$ & $\begin{array}{r}26 \\
4 \\
-\quad 4 \\
44\end{array}$ & $\begin{array}{r}57 \\
14 \\
4 \\
23 \\
98\end{array}$ & $\begin{array}{r}83 \\
18 \\
4 \\
27 \\
132\end{array}$ & $\begin{array}{l}16 \\
- \\
- \\
17\end{array}$ & $\begin{array}{r}34 \\
7 \\
1 \\
7 \\
49\end{array}$ & $\begin{array}{r}50 \\
7 \\
1 \\
8 \\
66\end{array}$ \\
\hline
\end{tabular}

${ }^{\star}$ Best corrected visual acuity.

$\mathrm{CF}=$ counting fingers; $\mathrm{HM}=$ hand movements; $\mathrm{PL}=$ perception of light; $\mathrm{NPL}=$ no perception of light; WHO definitions; visual impairment $>6 / 18-6 / 60$, severe visual impairment $>6 / 60-3 / 60$, blind $>3 / 60$. 
Table 3 Utimate amount of cicatrisation for those who required systemic immunosuppression compared with those that did not

\begin{tabular}{|c|c|c|c|c|c|c|}
\hline \multirow[b]{2}{*}{ Stage } & \multicolumn{2}{|c|}{ Foster's staging } & \multirow[b]{2}{*}{ Total } & \multicolumn{2}{|c|}{ Mondino's staging } & \multirow[b]{2}{*}{ Total } \\
\hline & $\begin{array}{l}\text { No systemic } \\
\text { treatment }\end{array}$ & $\begin{array}{l}\text { Systemic } \\
\text { treatment }\end{array}$ & & $\begin{array}{l}\text { No systemic } \\
\text { treatment }\end{array}$ & $\begin{array}{l}\text { Systemic } \\
\text { treatment }\end{array}$ & \\
\hline $\begin{array}{l}\text { I } \\
\text { II } \\
\text { III } \\
\text { IV } \\
\text { Total }\end{array}$ & $\begin{array}{c}2(6 \%) \\
18(53 \%) \\
11(32 \%) \\
3(9 \%) \\
34(100 \%)\end{array}$ & $\begin{array}{l}1(1 \%) \\
12(12 \%) \\
69(70 \%) \\
16(17 \%) \\
98(100 \%)\end{array}$ & $\begin{array}{c}3(2 \%) \\
30(23 \%) \\
80(61 \%) \\
19(14 \%) \\
132(100 \%)\end{array}$ & $\begin{array}{c}4(12 \%) \\
17(50 \%) \\
8(23 \%) \\
5(15 \%) \\
34(100 \%)\end{array}$ & $\begin{array}{c}1(1 \%) \\
9(9 \%) \\
37(38 \%) \\
51(52 \%) \\
98(100 \%)\end{array}$ & $\begin{array}{c}5(4 \%) \\
26(20 \%) \\
45(34 \%) \\
56(42 \%) \\
132(100 \%)\end{array}$ \\
\hline
\end{tabular}

signs such as symblepharon (stage III) and ankyloblepharon (stage IV). Ankyloblepharon is clearly uncommon compared with symblepharon (14\% versus $61 \%$ ). Of Foster's stages I-IV, the percentage of eyes with severe visual impairment or blindness per stage was $33 \%$, $6 \%, 18 \%$, and $74 \%$ and, therefore, ankyloblepharon is associated with a poorer visual acuity whereas symblepharon is not. For Mondino's stages I-IV severe visual impairment or blindness occurred in $0 \%, 8 \%, 20 \%$, and $36 \%$ of eyes, respectively. For example, an eye with a fornix less than $3 \mathrm{~mm}$ deep has an acuity of $6 / 18$ or better in $55 \%$. Therefore, there is a weak trend between a shallower inferior fornix and an impaired visual acuity although this was not statistically significant. This illustrates that the visual acuity may be maintained despite marked conjunctival shrinkage.

In addition there is no correlation between systemic manifestations of pemphigoid and visual loss. The reason for this is unclear and invites speculation. OCP is a basement membrane disease affecting both mucous membrane and skin. However, the corneal disease is unrelated to the various non-ocular manifestations and only weakly related to conjunctival cicatrisation. This may be due to antigenic differences between the tissues, or the corneal pathophysiology may be relatively independent of the immune driven basement membrane disease.

The development of limbitis is a poor prognostic sign of visual loss secondary to corneal disease. This has not been previously reported and can lead to visual loss secondary to corneal epithelial dysplasia. Therefore, limbitis demands aggressive therapy and this typically requires cyclophosphamide and high doses of prednisolone rather than sulphapyridine or dapsone. ${ }^{13}$ Limbitis was not associated with any of the systemic manifestations of OCP. This is consistent with the lack of correlation between the systemic manifestations of OCP and the visual acuity and it would appear that limbitis is an isolated ocular phenomenon.

Persistent epithelial defects were common $(13 \%)$ and were a major risk factor for poor visual acuity and ocular morbidity. It was particularly associated with very shallow fornices -

Table 4 Limbitis and the resulting visual acuity (per eye)

\begin{tabular}{lll}
\hline Visual acuity & Bilateral limbitis & No limbitis \\
\hline Better than $6 / 18$ & $15 / 37(41 \%)$ & $71 / 95(74 \%)$ \\
$>6 / 18-6 / 60$ & $6 / 37(16 \%)$ & $12 / 95(13 \%)$ \\
Worse than $6 / 60$ & $16 / 37(43 \%)^{\star}$ & $12 / 95(13 \%)$ \\
Total & $37 / 37(100 \%)$ & $95 / 95(100 \%)$ \\
\hline
\end{tabular}

«Statistically significant, $\mathrm{p}<0.001$.
$59 \%$ had less than $3 \mathrm{~mm}$ of inferior fornix. Seventy six per cent of eyes ultimately had a visual acuity of less than $6 / 60$ and $12 \%$ perforated acutely, despite most of these patients being on systemic immunosuppressive drugs. Microbial keratitis occurred in 3\% of eyes with perforation occurring in $0.8 \%$. In another series, Ormerod et al ${ }^{15}$ reported a $10 \%$ prevalence of keratitis for which the risk factors were trichiasis $(52 \%)$, topical steroid use $(27 \%)$, therapeutic contact lenses $(18 \%)$, 'inadvertent surgical management' ( $18 \%$ ), and lagophthalmos $(12 \%)$; the major complications included perforation $(4 / 33,12 \%)$, endophthalmitis $(2 / 33,6 \%)$, and reinfection $(5 / 33,15 \%)$. The incidence of keratitis is significantly higher in this series ( $p=0.03, \chi^{2}$ with Yates's correction) although the patient profile and severity of disease is similar. There is no adequate explanation for these differences.

Overall, $26 \%$ of patients with OCP did not require systemic immunosuppression. This subgroup was similar to the treated group with respect to age, duration of follow up, ultimate visual acuities, and the systemic manifestations of OCP. Therefore, these criteria cannot be used to predict whether a patient may require immunosuppression at some stage of the disease. However, there were large differences in the amount of cicatrisation between the groups. For example, $62 \%$ of the group who never required immunosuppression were Mondino's stage I or II compared with only $10 \%$ of the treated group (Table 3 ). Similarly, for Foster's staging, $87 \%$ of the treated group had symblepharon (stage III) compared with $41 \%$ of the untreated subgroup. These data are clinically useful. Patients who present with symblepharon are ultimately more likely to need systemic immunosuppression (87\% versus $41 \%, 2 \cdot 1 \times$ ), as are patients who present with lower fornices less than $5.5 \mathrm{~mm}$ deep $(90 \%$ versus $38 \%, 2 \cdot 3 \times)$. These groups probably have more rapidly progressive disease and a worse prognosis which accounts for their relatively advanced conjunctival shrinkage at presentation. Patients without symblepharon may have such slowly progressive disease that there will be no significant morbidity in their lifetime and, therefore, no justifying risks associated with current immunosuppressive regimens, both topical and systemic.

Using Mondino's staging system, 70\% of stage II eyes and $50 \%$ of stage III eyes progressed ( $n=7$ and 9). Foster's staging system was not helpful in detecting progression; only 2/46 eyes changed stages. For untreated patients, Mondino has reported similar progression in stage I $40-50 \%$, stage II $62-75 \%$, 
and stage III $73-78 \%{ }^{9}{ }^{16}$ whereas for patients treated with oral cyclophosphamide this was $25 \%, 10 \%$, and $75 \%$, respectively. ${ }^{16}$ Although patients with advanced disease require immunosuppression for inflammation more commonly than early disease, patients presenting with early disease have been shown to progress in this study and in others. ${ }^{916}$ It is probable that some patients with early disease, but without overt signs of inflammation, may progress and may benefit from immunosuppression as prophylaxis. This would require specific methods of monitoring disease activity.

1 Hardy KM, Perry HO, Pingree GC. Benign mucous membrane pemphigoid. Arch Dermatol 1971; 104: 467-75.

2 Lever WF. Pemphigus and pemphigoid: a review of the advances made since 1964. F Am Acad Dermatol 1979; 1: $2-31$.

3 Mondino BJ, Ross AN, Rabin BS, Brown SI. Autoimmune phenomena in ocular cicatricial pemphigoid. $A m \mathcal{F}$ Ophthalmol 1977; 83: 443-50.

4 Leonard JN, Hobday CM, Haffenden GP. Immunofluorescent studies in ocular cicatricial pemImmunofluorescent studies in ocular cicatricial pem-

5 Rice BA, Foster CS. Immunopathology of cicatricial pem- phigoid affecting the conjunctiva. Ophthalmology 1990; 97: 1476-83.

6 Sacks EH, Jakobiec FA, Wieczorek R, Donnenfeld E, Perry $H$, Knowles DM. Immunophenotypic analysis of the inflammatory infiltrate in ocular cicatricial pemphigoid. Further evidence for a T-cell mediated disease Ophthalmology 1989; 96: 236-43.

7 Bernauer W, Wright P, Dart JKG, Leonard JN, Lightman $S$. The conjunctiva in acute and chronic mucous membrane pemphigoid: an immunohistochemical analysis. Ophthalmology 1993; 100: 339-46.

8 Foster CS. Cicatricial pemphigoid. Trans Am Ophthalmol Soc 1986; 84: 527-663.

9 Mondino BJ, Brown SI. Ocular cicatricial pemphigoid. Ophthalmology 1981; 88: 95-100.

10 Mondino BJ, Brown SI. Immunosuppressive therapy in ocular cicatricial pemphigoid. Am $\mathcal{f}$ Ophthalmol 1983; 96: 453-9.

11 Foster CS, Wilson LA, Ekins MB. Immunosuppressive therapy for progressive ocular cicatricial pemphigoid. Ophthalmology 1982; 89: 340-53.

12 Schwab IR, Linberg JV, Gioia VM, Benson WH, Chao GM. Foreshortening of the inferior conjunctival fornix associated with chronic glaucoma medications. associated with chronic gla

13 Elder MJ, Lightman SL, Dart JK. The role of cyclophosphamide and high dose steroid in ocular cicatricial pemphigoid. $\mathrm{Br} \mathcal{F}$ Ophthalmol 1995; 79: 264-6.

14 Elder MJ, Leonard JN, Dart JK. Sulphapyridine - a new agent for the treatment of ocular cicatricial pemphigoid. Br $\mathcal{O}$ Ophthalmol (in press).

15 Omerod LD, Fong LP, Foster CS. Corneal infection in mucosal scarring disorders and Sjogren's syndrome. $A m \mathcal{F}$ Ophthalmol 1988; 105: 512-8.

16 Mondino BJ. Cicatricial pemphigoid and erythema multiforme. Ophthalmology 1990; 97: 939-52. 